\title{
Renewable Energy in Africa; Potential, Impact and The Way Forward
}

\author{
Nana Twum Duah ${ }^{1 *}$, Prince Kofi Asamoah ${ }^{2}$ \\ ${ }^{1}$ Department of Computer and Electrical Engineering, University of Energy and Natural Resources, Sunyani, Ghana. \\ ${ }^{2}$ Department of Electrical Engineering, Kwame Nkrumah University of Science and Technology, Kumasi, Ghana.
}

"Corresponding author: nana.twumduah@yahoo.com

\begin{abstract}
Renewable energy sources are abundantly available in Africa due to the continent's geographical location. For example, it is the sunniest continent on earth with about $85 \%$ of the landscape having solar insolation of approximately 2000 $\mathrm{kWh} / \mathrm{m}^{2}$ in a year and also with a large stretch of coastline where both wind and wave energy resources are abundant. The available renewable energy sources are underutilised due to many challenges such as inadequate funds, bad or nonexistent policies, and unavailability of skilled labour. This paper, therefore, aims to investigate the impact of renewable energy on Africa and the world as a whole if these renewables are utilised efficiently. The paper again will look into the reasons why renewable energies in Africa are underutilised and recommend possible solutions to these problems as well. Moreover, the paper will discuss the social, economic and environmental impacts of utilising renewable energy in Africa regarding jobs creation, infrastructure development, revenue creation, and reduction of carbon emissions into the atmosphere. The efficient utilization of these renewable energy resources will make Africa a powerhouse of clean energy production for its use and export.
\end{abstract}

Keywords: Economic, Environmental, Renewable Energy, Social, Solar Insolation.

Article History: received 26 July 2017; accepted 21 March 2018; published 16 April 2018.

(C) 2018 Penerbit UTM Press. All rights reserved.

\section{INTRODUCTION}

Africa is the second largest continent on the globe [1] with a population of 1.2 billion in fifty-four (54) countries [2]. It is surrounded by the Mediterranean Sea on the north, the Atlantic Ocean on the west, the Indian Ocean on the east and south-east, and Suez Canal and the Red Sea in the northeast. Located in the continent exist the world longest river, Nile and the largest desert, Sahara [1]. In 2010, 57\% (590 million) of the population in Africa had access to electricity and 32\% (370 million) relied on biomass for cooking [3]. With the current trend, it is estimated that by 2030, $42 \%$ (655 million) of the population will not have access to electricity and 56\% (866 million) without clean cooking facilities as shown in figure 1, preventing many Africans from enjoying a healthy and productive life.

Africa has economic growth of $4 \%$ annually with gross domestic product (GDP) growth estimated to grow by three (3) times by 2030 [3]. With population of the continent estimated to double in the near future, the economic and social growth of Africa depends greatly on the availability of energy since almost all productive activities require energy [3], [4]. In 2010 and 2011, \$224.5 billion and \$279 billion was invested in Renewable Energy (RE) respectively whiles 244 billion was invested in 2012 [5].
Even though there has been a major investment in RE in recent years to promote clean energy usage, RE resources in Africa is still under-exploited. As it can be seen in figure 2 only South Africa (SA) from Africa made it to the top 10 for new investment in RE in 2012 indicating low patronage of renewables in Africa.

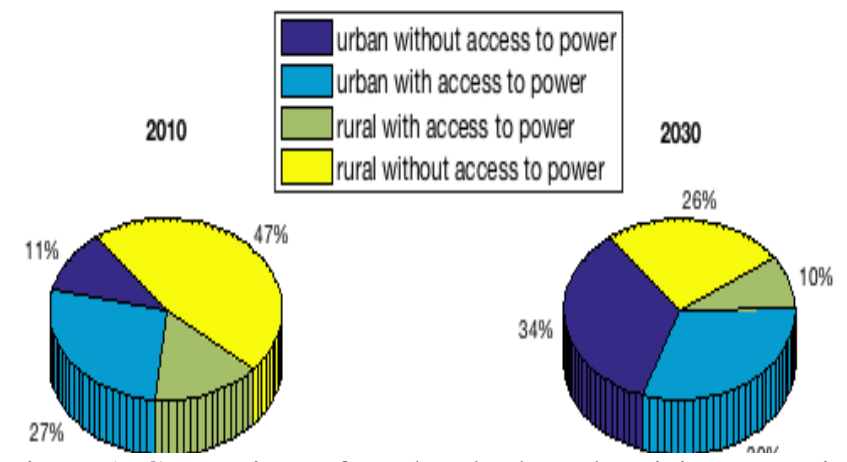

Figure 1. Comparison of rural and urban electricity access in 2010 and 2030, if current trends continue [3] 


\section{POTENTIAL OF RENEWABLE ENERGY IN}

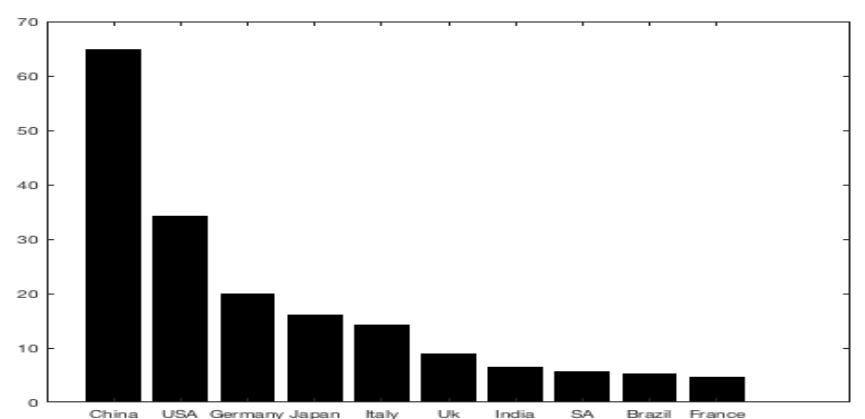

Figure 2. Investment in RE By countries in \$BN [5]

\section{AFRICA}

The geographical location of Africa makes it rich in renewable energy sources mainly hydro, solar, the wind, waves, and geothermal. Africa is sunniest continent on earth with about $85 \%$ of the mainland landscape having solar irradiation of approximately $6-8 \mathrm{kWh} / \mathrm{m}^{2} /$ day and also with a large stretch of coastline where both wind and wave energy resources are abundant [6],[4]. In 2007, it could be estimated that the total amount of electricity consumed by France, Germany, United Kingdom and Italy was equivalent to the total amount of electricity that can be generated from hydropower in Africa [6].

Africa is enriched with abundant renewable energy sources with an estimated 1.1 Gigawatts of hydroelectric capacity and 900 Megawatts of geothermal potential with only $7 \%$ of hydro and $0.6 \%$ of geothermal potential being harnessed currently [7],[6]. Africa has 17 out of 35 countries in the world leading in solar, wind, hydro and geothermal energy resources [4]. Shown in figure 3 is identified RE potential in Africa.

There is a vast potential of wind power resources left untapped in sub-Saharan Africa. Climatological and meteorological data from Africa wind atlas indicate that countries like South Africa, Lesotho, Madagascar, Somalia, Cape Verde, Mauritania and Chad have the best wind energy resources left untapped. [4]

Africa has a foresight of increasing it electricity supply to overcome shortages to ensure the entire population access to electricity, and also reduce the continent dependent on fossil fuel. This is to allow the continent to supply power but emitting low -carbon. According to IRENA Africa 2030 Remap, it is projected that the installed power capacity in Africa should increase to $610 \mathrm{GW}$ in 2030 . That means there is opportunity to plan and explore RE in the continent. Figure 4 gives an overview of generation capacity developments in the five regions, namely, North, West, central, East and southern Africa between the period 2013 to 2030 . From the total capacity of $310 \mathrm{GW}, 101 \mathrm{GW}$ and $100 \mathrm{GW}$ represent hydro and wind resources respectively. Full deployment of these Renewables would open up potential investment opportunities in the market up to USD 32 billion per annum. Table 1 shows the total investment needed between 2015 and 2030 in the power sector for renewables that include initial startup cost comprising transmission and distribution (T \& D) costs [8].

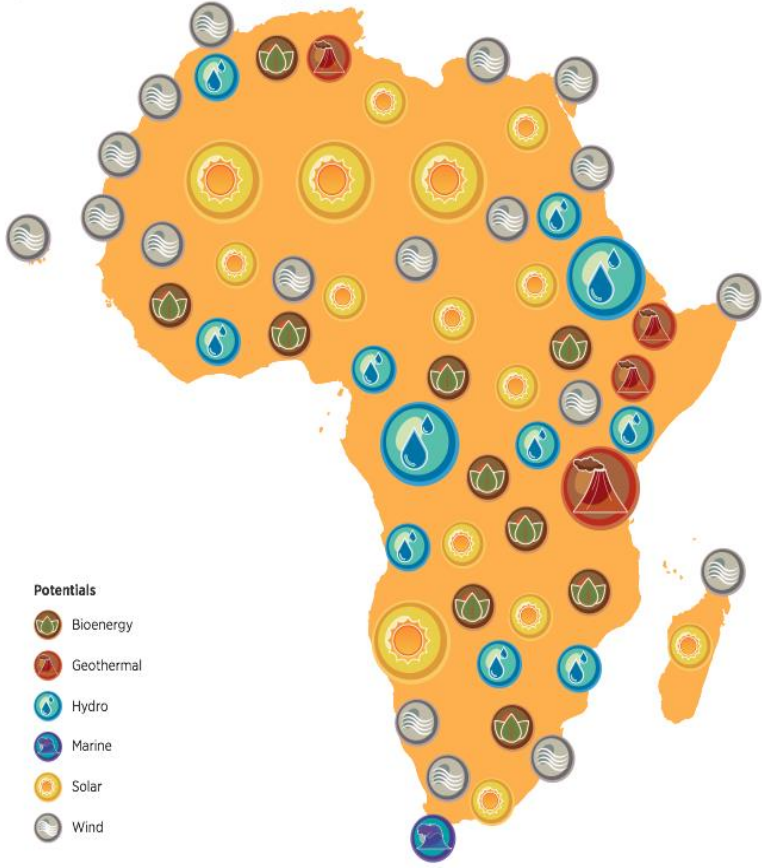

Figure 3. Distribution of identified Renewable potential in Africa [3]

\subsection{Why RE in Africa is under-exploited?}

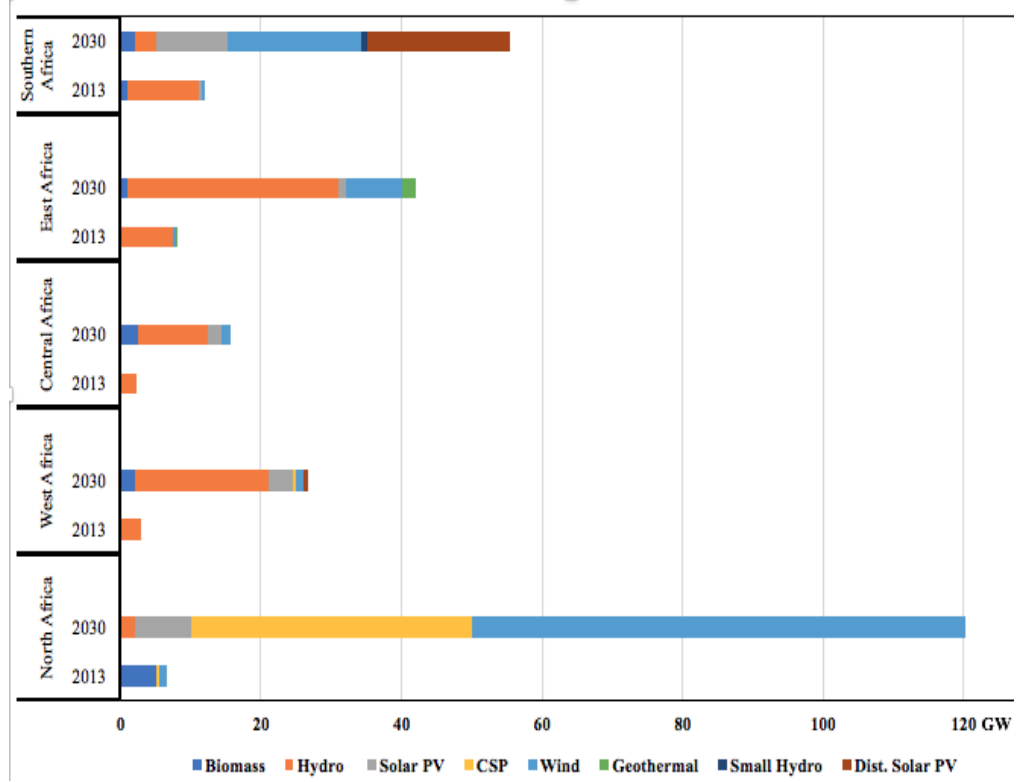

Figure 4. Overview of RE generation capacity development in Africa [8]

Table 1. Cumulative investment needs between 2015 and 2030 [8]

\begin{tabular}{|c|c|c|c|}
\hline \multirow{2}{*}{ Region } & \multicolumn{3}{|c|}{ Investment billion USD (2015 - 2030) } \\
\cline { 2 - 4 } & Large Hydro & $\begin{array}{c}\text { Other } \\
\text { Renewables }\end{array}$ & T \& D \\
\hline North Africa & 2 & 218 & 186 \\
\hline West Africa & 36 & 31 & 52 \\
\hline Central Africa & 13 & 17 & 14 \\
\hline East Africa & 36 & 21 & 49 \\
\hline Southern Africa & 18 & 94 & 74 \\
\hline Total & 106 & 381 & 375 \\
\hline
\end{tabular}


Many factors have contributed to the underutilization of $\mathrm{RE}$ in Africa. One of the main hindrances to the development of RE in Africa is the high initial capital required to procure equipment and set up. [7], [9]. Considering the economic status of many African countries it becomes difficult to mobilize huge funds to invest in such projects [9]. Even though foreign investors are willing to invest in the area, poor institutional framework and infrastructure have been a major drawback. [7], [10]. Also, there are bad policies and planning to protect the interest of these investors [11]. Up until 2013 only South Africa and Morocco had developed and introduced independent power producer procurement programmes to attract foreign investors to develop RE [10].

Political instability in some parts of Africa caused mainly by civil wars is one of the factors. These instabilities hinder the social, economic and infrastructural development of the continent thereby affecting the growth of RE as well [6]. Other factors include; lack of skilledlabour and technologies to harness the RE resources [7], [9]. The skilled workers and technical requirement to exploit RE in Africa are not available in most of the developing countries. Even though the labour and technologies can be imported from developed countries, it involves huge sums of money.

Over the years, Africa has depended much on traditional biomass as the continent's main alternative source of energy for domestic and commercial use [11]. Since the usage of these traditional sources of energy has been part of the people for a long time, it has become a major challenge for Africans to accept new forms of energy.

\section{IMPACTS OF UTILISING RE IN AFRICA}

"Energy is at the heart of widespread social, economic and climate problems" [9]. Exploiting RE is a key to alleviating poverty, development of rural areas and maintaining a safe environment to promote Economic, Social and environmental development in Africa and the world as a whole [9].

\subsection{Economic}

Poverty is a major issue that has confronted the African continent for a long time. Access to affordable and sustainable energy in Africa has been said to be one of the ways to reduces poverty [6], [12]. Access to electricity will spur the growth of small and medium enterprises promoting economic growth in rural communities [13]. Availability of energy will also enhance productive activities and essential services. For instance, women and girls in Africa spend most of their time fetching wood for domestic purpose. Getting access to modern energy service will help women and girls to devote their time to schooling and income generating services [11]. Currently, in most African countries, electricity is generated from fuel driven generators which are expensive to operate. In Nigeria and Democratic Republic of Congo (DRC) for instance, the cost of electricity from diesel generators are $\$ 0.03$ per $\mathrm{kWh}$ and $\$ 0.9$ per $\mathrm{kWh}$ respectively whiles the cost of electricity from $\mathrm{RE}$ is about 0.1 per $\mathrm{kWh}$ [10], therefore using RE will save cost.Also, effective usage of RE in Africa will limit the importation of fuel promoting the growth of African economy by putting these monies in the various economics [3], [7], [14].

Again, energy security is one major factor that attracts foreign investors into a country. Exploitation of renewables to produce reliable electricity, the availability of cheap labour and raw materials (which already exist), will attract investors to set up manufacturing companies, which will create jobs and fuel the local economies.

Moreover, RE sector can become an integral part of job creation in Africa right from construction through to operation and maintenance required for these projects [14]. It is estimated in [3] that, in the construction of hydropower stations, the civil works takes $65 \%$ of the value of the entire project. This civil works which can be carried out with the local human resource will create jobs for the local industry and people.

\subsection{Environmental}

Climate change has recently become one of the world's major problems [16], both developed and developing countries have taken necessary steps to address these issues by the reduction in the use of fossil fuel. While other factors such as agriculture, use of chemicals and land-use changes contribute to greenhouse gas emission, $70 \%$ of climate change is contributed by the use of fossil fuel [14]. The energy demand needed globally is predicted to grow as a result of industrialisation and population growth, therefore, the need arises to resort to clean energy. Deploying RE as an alternative source of the traditional forms of energy will facilitate the reduction of carbon emissions.

Africa depends much more on biomass especially in the form of charcoal for domestic use. The usage of biomass has over the period caused the emission of $\mathrm{CO}_{2}$ resulting in air pollution and encouraged deforestation leading to land degradation. In some main African cities like Lusaka in Zambia, Dar-es-Salaam in Tanzania and Nairobi in Kenya, the use of charcoal contributes enormously to the degradation of woodlands and forest [7]. Exploiting Renewables will provide clean, relatively cheap, safe alternatives to the current form of energy destroying the climate [14].

\subsection{Social}

The social impact of developing RE on the improvement of the quality of life in Africa makes it a necessity, not an option [3]. It was estimated in 2008 by world bank that 1.6 billion people living mainly in sub-Sahara Africa and south have no access to electricity, making the welfare development of these people hard to improve [12]. RE projects especially rural electrification play a major role in providing essential services to the people in such communities. These core services can be classified into household and community level services. Regarding household services, access to RE provides clean electricity, heating, cooking, better lighting systems at homes, improves audio-visual services and better preservation of food [12], [14]. These will help prevent the likelihood of fire outbreaks caused by the use of candles and other traditional sources of light. It will also assist in 
the dissemination of information and education of the rural population.

Additionally, better preservation of food will promote the hygiene and health of the local people. On the other hand, regarding community-level services; access to electricity will improve education, health system, communication, entertainment and public security. In the health sector, it will help in the improvement of the preservation of medicines and enhance the reliability of power supply in hospitals which will intend save lives [12], [14].

Moreover, developing RE attracts investors; skilled labour into the region. RE projects bring about the development of infrastructures such as roads, hospitals and hostels. The health conditions for the local people can be improved by reducing air pollution from the traditional source of energy. This can be achieved by replacing the traditional solid fuel like wood, fuel, fossil fuel and charcoal with clean and sustainable energy. In addition, the quality of living standard of the individual can be improved significantly when the time spent in gathering wood is channelled into other productive ventures [12].

\section{THE WAY FORWARD}

The need for the utilisation of RE is very significant and vital in the development of Africa. In order to achieve that, some steps and interventions should be made to promote the exploitation of RE. Some of these measures are discussed below:

There should be sound policies, regulatory and institutional framework; To successfully utilise RE in Africa, consistent, enabling policies and regulatory framework are vital to building favourable market conditions for investors [8], [11]. Well-structured policies and regulatory framework will enable private and industrial sectors to enter into RE projects on the continent. Governments in Africa should incorporate RE development policies and plans into national policies such as the removal of taxes on RE products, and subsidize the cost of materials used in RE projects. Currently, Kenya and Zimbabwe have removed taxes on PV systems to encourage investors [11]. To improve the reliability, quality and acceptance from consumers, the development of standards, testing and certification of RE technology (RET) is central. African countries should build technical institutions to promote testing, operation and maintenance of RET. Also, African countries should create a conducive environment to promote workshops and training for local engineers and technical staff in the field of RET [12]. Furthermore, there should be the promotion of political stability in African countries to attract and minimise the risk of investment.

Financing and Investment; One of the biggest challenges in the exploitation of RE is the availability of funds in developing countries. African Development Bank (ADB) estimated that the total investment needed in Africa to succeed in the achievement of the accessibility to reliable and clean electric power by 2030 is $\$ 547$ billion. From the estimation, the amount needed per year is $\$ 53$ billion but there is an average investment of $\$ 2$ billion every year [11]. Clearly, any attempt to exploit RE cannot be achieved without financing and investing in the energy sector. Therefore, there is the need to understand these financial barriers in order to eradicate them. There should be enough funds to invest into the stakeholders in RE sector such as financial intermediaries (like the bank, and micro lenders), suppliers, dealers, service companies and end users [9]. For instance, there should be an available and flexible loan and grants to cover the initial capital cost. The global environment facility (GEF) financed $5 \%$ of the total investment cost of RE projects in some developing countries [9]. Additionally, there should be schemes by financial institutions in Africa to sponsor the purchases of RE equipment. For example, GEF has developed microfinance institutions in countries such as Bangladesh and Uganda to provide funds for the sales of a solar home energy system [9].

\section{CONCLUSION}

Exploitation of RE in Africa has been faced with numerous challenges including political, technical, social and economic issues undermining the development of the continent. Therefore, the need arises to tackle and remove these barriers through enabling policies, providing regulatory framework and financing and investing in RE sector in Africa. This paper has established that to build a strong economy, create a green and safe environment and good infrastructures in Africa, utilising RE is the key.

\section{REFERENCES}

[1] World atlas. (2016, April) Africa map / map of Africa. [Online]. Available: http://www.worldatlas. com/webimage/countrys/af.htm [Accessed 19th April 2016].

[2] D. you, L. Hug and D. Anthony, "Generation 2030 Africa child demographics in Africa," UNICEF, New York, 2014.

[3] IRENA, "Africa's Renewable Future the path to sustainable growth," International Renewable Energy Agency, Abu Dhabi, 2013.

[4] F.I. oluwajobi, and F. Omowole O.M Longe, "Electricity Access in Sub-Saharan Africa- Case for Renewable Energy Sources Microgrid," in IEEE International Conference on Emerging \& Sustainable Technologies for Power \& ICT in a Developing Society, Abuja, 2013, p. 4.

[5] Bloomberg New Energy Finance, "Global Trends in Renewable Energy Investment," Frankfurt SchoolUNEP Collaborating Center, Frankfurt, 2013.

[6] V.K Fouskas, "Politics of conflict: A survey Routledge," 2010, p. 304.

[7] S.and W. Kithyoma Karekezi, "Renewable Energy in Africa: prospects and Limits," African Energy Policy Network, Dakar, June 2003."International Renewable Energy Agency," IRENA, Abu Dhabi, 2015.

[9] Gef, "Investing in Renewable Energy," Global Environments Facility, 2009.

[10] Baker and Mckenzie, "The Future of Clean Energy in Africa," Clean energy pipeline, Chicago, 2013. 
[11] "Scaling up Renewable Energy in Africa," African Unions Industrial development organisation, Addis Ababa, 2009.

[12] C. Dienst, J. Konig and W. Ortiz J. Terrapon-Pfaff, "Impacts and Sustainability of small-scale renewable energy projects in developing countries," Elsevier, August 2014.

[13] P. Buchana and T. S. ustun, "The role of Microgrid and Renewable Energy in Addressing Sub-Saharan Africa's Current and Future," IEEE Renewable Energy Congress (IREC) 6th Congress, 2015.

[14] EREC, "Renewable Energy, The solution to climate change," European Renewable Energy Council, Brussel.

[15] OECD, "Linking Renewable Energy to Rural Development," Organisation for Economic Cooperation and Development, Paris, 2012.

[16] K.P.S Parmar and N.K Yadav M.K Jangra, "Reduction of Global Warming by Using Renewable Energy Resources: A mathematic Approach," International Journal of Computer Science and Telecommunications, vol. 3 , no. 2, p. 41, February 2012.

[17] Ipeck. (2011, March) solar Energy world. [Online]. Available: http://www.solarenergyworld.com/ 2011/09/01/how-solar-energy-impacts-theenvironment [Accessed 19th April, 2016].

[18] Practical Action. Practical Action. [Online]. Available: http://practicalaction.org/lighting-up-thedark [Accessed 19th April 2016]

[19] ASD. African solar Designs. [Online]. Available: http://www.africansolardesigns.com [Accessed 19th April 2016].

[20] Tim De Chant. genesis nanotech. [Online]. Available: https://genesisnanotech.wordpress. com/tag/nrel [Accessed 19th April 2016]. 